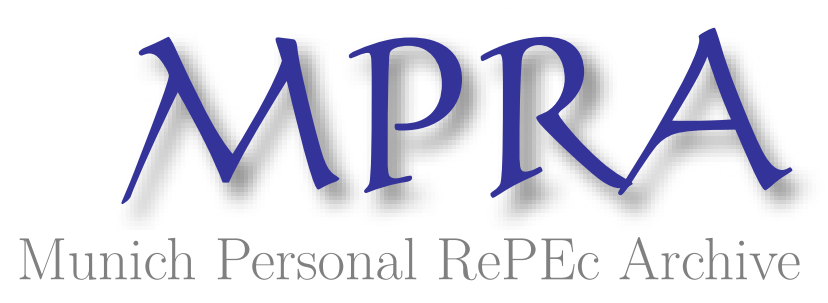

\title{
How accounting accuracy affects DSGE models
}

Kim, Minseong

29 March 2016

Online at https://mpra.ub.uni-muenchen.de/70356/

MPRA Paper No. 70356, posted 29 Mar 2016 15:42 UTC 


\title{
How accounting accuracy affects DSGE models
}

\author{
Minseong Kim
}

$2016 / 03 / 29$

\begin{abstract}
This paper explores how accounting consistency affects DSGE models. As many DSGE models descended from real business cycle models, I explore a simple labor-only RBC model with an exogenous external sector introduced. The conclusion reached in this paper is that once an external sector is introduced, DSGE models may suffer from accounting inconsistency, unless disequilibrium or some non-orthodox theory of price level, real monetary supply or bonds is accepted.
\end{abstract}

\section{Accounting consistency of a simple labor-only RBC model with exogenous government and without money}

The model is the infinite-life representative agent framework. The household obtains utility $u\left(C_{t}, N_{t}\right)$ at time $t$, where $C_{t}$ is consumption and $N_{t}$ is labor. Total utility of the household is given by

$$
U=\sum_{t=0}^{\infty} \beta^{t} u\left(C_{t}, N_{t}\right)
$$

where $\beta$ is time preference. In this economy, nominal factor can be ignored, and thus every variable will be a real variable.

$$
u\left(C_{t}, N_{t}\right)=\frac{C_{t}^{1-\sigma}}{1-\sigma}-\frac{N_{t}^{1+\varphi}}{1+\varphi}
$$

The household has budget constraint as follows:

$$
C_{t}+R_{t}^{-1} B_{t} \leq B_{t-1}+W_{t} N_{t}+\Pi_{t}
$$

where $B_{t}$ is bond, $R_{t}$ is real interest rate, $\Pi_{t}$ is dividend received from the firm. One can immediately stop here and notice that for the fixed income in the righthand side, there is no reason why the household would buy $B_{t}$, unless it affects future consumptions. The rest of this section is developed to demonstrate in 
the economy specified that buying more $B_{t}$ does not increase or decrease future consumption and does not increase or decrease future labor quantity. Future consumption and labor quantity are affected only by expected technology $A_{t+k}$ and expected government deficit spending $G_{t+k}$ that are assumed to be moneyfinanced solely (in other words, finance deficit by printing money), instead of being debt-financed. I will assume that $g_{t}$ is exogenous, but that the government announced the full path of $g_{t}$ from present to the infinite future.

Let the lower-case $z$ of upper-case variables $Z$ represent $z=\log (z)$. The optimality conditions in the log form are:

$$
\begin{aligned}
w_{t} & =\sigma c_{t}+\varphi n_{t} \\
E_{t}\left[c_{t+1}\right] & =c_{t}+\frac{1}{\sigma}\left(r_{t}-\rho\right)
\end{aligned}
$$

where $\rho=-\log \beta$.

Let the firm maximize profit:

$$
\Pi_{t}=Y_{t}-W_{t} N_{t}
$$

with

$$
Y_{t}=C_{t}+G_{t}=A_{t} N_{t}^{1-\alpha}
$$

where $G_{t}$ is government deficit spending, financed through money. I will not consider inflation as price level $P_{t}$ is assumed to be uniform across sectors. The optimality condition is

$$
w_{t}=a_{t}-\alpha n_{t}+\log (1-\alpha)
$$

By log-linearization assumption, assume:

$$
\begin{gathered}
y_{t}=c c_{t}+g g_{t}=a_{t}+(1-\alpha) n_{t} \\
c_{t}=\frac{a_{t}+(1-\alpha) n_{t}-g g_{t}}{c}
\end{gathered}
$$

where $c$ and $g$ are defined around steady-state values.

Labor-market clearing requires:

$$
\begin{gathered}
\sigma\left[\frac{a_{t}+(1-\alpha) n_{t}-g g_{t}}{c}\right]+\varphi n_{t}=a_{t}-\alpha n_{t}+\log (1-\alpha) \\
{\left[\frac{\sigma}{c}(1-\alpha)+\varphi+\alpha\right] n_{t}=\left[1-\frac{\sigma}{c}\right] a_{t}+\frac{\sigma g}{c} g_{t}+\log (1-\alpha)} \\
n_{t}=\frac{\left[1-\frac{\sigma}{c}\right] a_{t}+\frac{\sigma g}{c} g_{t}+\log (1-\alpha)}{\frac{\sigma}{c}(1-\alpha)+\varphi+\alpha}
\end{gathered}
$$

If technology $a_{t}$ is assumed to be exogenous, but with known future expected values, then $y_{t}$ is uniquely specified. Since $g_{t}$ is already known, $c_{t}$ is already known. Thus, just from knowledge of $g_{t}$, present and expected future $c_{t}$ can 
be calculated. Thus it is now established that $B_{t}$ does not affect real economy. This result is not affected by whether one takes linearization approximation or not.

The problem, then is the following. For accounting consistency,

$$
Y_{t}=C_{t}+S_{t}=C_{t}+G_{t}
$$

is required (which means $Y_{t}>C_{t}$ whenever $G_{t}>0$ ), assuming there is no foreign sector and there is no investment (because this economy is labor-only economy). $S_{t}$ refers to savings in national accounting. Thus $G_{t}=S_{t}$. But notice Equation 3, replicated below:

$$
C_{t}+R_{t}^{-1} B_{t} \leq B_{t-1}+W_{t} N_{t}+\Pi_{t}
$$

We know that

$$
Y_{t}=W_{t} N_{t}+\Pi_{t}
$$

This is true by definition. Thus the budget constraint can be re-written as

$$
C_{t}+R_{t}^{-1} B_{t} \leq Y_{t}+B_{t-1}
$$

$Y_{t}+B_{t-1}$ can be considered as available budget. For the fixed budget $Y_{t}+B_{t-1}$, there is simply no reason why the household would buy $B_{t}$, as this would decrease the household's utility. Furthermore, according to the calculation above, $C_{t+1}$ is unaffected by the quantity of $B_{t}$. Thus, $B_{t}=0$ in equilibrium for all time $t$. But this runs in contradiction to Equation 14, as now

$$
C_{t}=Y_{t}+B_{t-1} \geq Y_{t}
$$

Whenever $G_{t}>0$, this causes contradiction.

The inevitable conclusion is that in this basic economy, unless government deficit spending is zero $\left(G_{t}=0\right)$, disequilibrium is unavoidable, unless the idea of forced savings is adopted.

\subsection{Interpreting government deficit spending as exports}

It can easily be seen that $G$ can be replaced with $X$, exports. Assume that $X$ is exogenously given and there is zero import. (I will save $M$ for representing money quantity.) One can assume that the foreign sector shares the same currency as the domestic sector, and all central banks have money-printing rights, and that the representative agent of each country cannot change its citizenship. Then it is clear that one faces the exactly same accounting problem.

\section{Gali (2014)'s review of money-financed deficit spending}

The discussion above is important, as this problem is not properly recognized when dealing with money-financed government spending problems. Gali (2014) 
[1] does the exactly same analysis as in the above analysis in the classical monetary economy section, with some utility simplification and additions and some further analysis. Mainly, money is introduced into utility, so utility now looks as:

$$
u\left(C_{t}, N_{t}\right)=\frac{C_{t}^{1-\sigma}}{1-\sigma}+\frac{M_{t}^{1-\nu}}{1-\nu}-\frac{N_{t}^{1+\varphi}}{1+\varphi}
$$

where $M_{t}$ is "real" value of money (in Gali (2014), it is $M_{t} / P_{t}$ ), with budget constraint:

$$
C_{t}+R_{t}^{-1} B_{t}+M_{t} \leq B_{t-1}+W_{t} N_{t}+\Pi_{t}+M_{t-1}
$$

But even with this modification, the only extra optimality condition one obtains is:

$$
M_{t}=\left(\frac{C_{t}{ }^{\sigma}}{1-R_{t}^{-1}}\right)^{1 / \nu}
$$

By given knowledge and market clearing, $C_{t}$ and $E_{t} C_{t+1}$ are known. Thus, $R_{t}$ is also known. This means $M_{t}$ is also known. $B_{t}=0$ also in "equilibrium." Let us re-write the budget constraint into equality (as the household does best to maximize its utility):

$$
C_{t}+M_{t}-M_{t-1}=C_{t}+S_{t}=C_{t}+G_{t}=Y_{t}
$$

Thus, $G_{t}=M_{t}-M_{t-1}$ must be satisfied. But notice again that $C_{t}$ and $R_{t}$ are determined independently of $M_{t}$. Suppose that it was found that $G_{t}=$ $M_{t}-M_{t-1}$. Then one can adjust $\nu$ to make this equality to be untrue, given that the path of $G_{t}$ remains the same as before.

\subsubsection{Fiscal theory of real money supply?}

In some ways, these results suggest that some form of fiscal theory of real money supply (here, $M_{t}$ ) is needed to properly form a equilibrium - that the current money-financed deficit spending defines the change in real money supply $\left(M_{t}-\right.$ $\left.M_{t-1}\right)$. If this were true, then central banks, by setting nominal money supply $M_{t} P_{t}$ defines price level $P_{t}$. In a way, this is similar to fiscal theory of price level.

Intuitively, the theory does make sense. After all, $G_{t}$ is assumed to be all money-financed and this all adds up to real money supply. The problem rather here is why it is the only change possible in net aggregate. Though explaining this constraint may reveal how price level is affected by government spending as equilibrium adjustments.

Also, if one replaces $G$ with $X$, then the theory converts to current account (CA) surplus/deficit theory of real money supply. One can try to combine two as external surplus/deficit theory of real money supply. But whether this theory is plausible would be left as a question. Notice that the form of a theory can change depending on how utility is specified, so $G_{t}=M_{t}-M_{t-1}$ does not always come out as a constraint. 


\section{Debt-financed deficit spending via bonds, with interest money-financed}

So far, in equilibrium $B_{t}=0$. Suppose that the government finances its deficit spending $G_{t}$ by bonds, so $G_{t}=R_{t}^{-1} B_{t}$, if there are equivalent demands, and finance interest by printing money. Again, however, the household has zero demand on $B_{t}$. Thus to form an equilibrium properly without $G_{t}$ constrained to zero or to adopt a non-orthodox theory of money supply, let us introduce $B_{t}$ into utility.

$$
u\left(C_{t}, N_{t}\right)=\frac{C_{t}^{1-\sigma}}{1-\sigma}+\frac{B_{t}{ }^{1-\nu}}{1-\nu}-\frac{N_{t}^{1+\varphi}}{1+\varphi}
$$

with the previous budget constraint:

$$
C_{t}+R_{t}^{-1} B_{t} \leq B_{t-1}+W_{t} N_{t}+\Pi_{t}
$$

Here, I drop $M_{t}$ from utility. But the optimality conditions of the household do change significantly as follows:

$$
B_{t}^{-\nu}-C_{t}^{-\sigma} R_{t}^{-1}+\beta E_{t}\left[C_{t+1}{ }^{-\sigma}\right]=0
$$

Other optimality conditions remain the same. Notice that $C_{t}$ and $C_{t+1}$ are unaffected by the changed optimality condition. The affected is $R_{t}$, and the below is the log-linearizied approximation of $r_{t}$ :

$$
r_{t}=\frac{\sigma\left(E_{t}\left[c_{t+1}\right]-c_{t}\right)+\rho+\nu g_{t}}{1-\nu}
$$

If $g_{t}$ is replaced with $x_{t}$, then the foreign sector is buying the goods in the domestic sector and selling $B_{t}$ that the domestic sector willingly takes. Without further restriction, it is certainly possible that the domestic sector continuously buys $B_{t}$ at all time $t$ that the foreign sector wishes to sell to finance $x_{t}$ (for the foreign sector this is import). Thus, CA deficits go without the problem in this economy, though this certainly is only theoretical.

The inclusion of $B_{t}$ in utility results in a different conclusion of welfare effects of fiscal deficit, but I will not explore this question.

\section{References}

[1] Gali, J (2014), "The Effects of a Money-Financed Fiscal Stimulus", CEPR Discussion Paper 10165, September. 